Mechanism and Processing Dependence of Biaxial Texture Development in Magnesium Oxide Thin Films Grown by Inclined-Substrate Deposition*

M. P. Chudzik,\# R. Koritala, L. P. Luo, D. J. Miller, and U. Balachandran

Argonne National Laboratory, Argonne, IL 60439

C. R. Kannewurf

Northwestern University, Evanston, IL 60208-3118

September 2000

The submitted manuscript has been created by the
University of Chicago as Operator of Argonne Nationa
Laboratory ("Argonne") under Contract No. W-31-109-
ENG-38 with the U.S. Department of Energy. The U.S.
Government retains for itself, and others acting on its
behalf, a paid-up, nonexclusive, irrevocable worldwide
license in said article to reproduce, prepare derivative
works, distribute copies to the public, and perform publicly
and display publicly, by or on behalf of the Government.

Paper to be presented at Applied Superconductivity Conference ASC 2000, Virginia Beach, VA, September 17-22, 2000; to be published in IEEE Trans. Appl. Supercond.

*Work supported by the U.S. Department of Energy (DOE), Energy Efficiency and Renewable Energy, as part of a DOE program to develop electric power technology, under Contract W-31-109-Eng-38.

"Current address: Semiconductor Research and Development Center, IBM Microelectronics, 33A, 2070 RTE 52, Hopewell Junction, NY 12533. 


\section{DISCLAIMER}

This report was prepared as an account of work sponsored by an agency of the United States Government. Neither the United States Government nor any agency thereof, nor any of their employees, make any warranty, express or implied, or assumes any legal liability or responsibility for the accuracy, completeness, or usefulness of any information, apparatus, product, or process disclosed, or represents that its use would not infringe privately owned rights. Reference herein to any specific commercial product, process, or service by trade name, trademark, manufacturer, or otherwise does not necessarily constitute or imply its endorsement, recommendation, or favoring by the United States Government or any agency thereof. The views and opinions of authors expressed herein do not necessarily state or reflect those of the United States Government or any agency thereof. 


\section{DISCLAIMER}

Portions of this document may be illegible in electronic image products. Images are produced from the best available original document. 


\title{
Mechanism and Processing Dependence of Biaxial Texture Development in Magnesium Oxide Thin Films Grown by Inclined-Substrate Deposition
}

\author{
M.P. Chudzik, " R. Koritala, L.P. Luo, D.J. Miller, and U. Balachandran \\ Argonne National Laboratory, Argonne, IL 60439 \\ C. R. Kannewurf \\ RECEIVED \\ NOV 082000 \\ Electrical and Computer Engineering Department, Northwestern University, Evanston, IL 60208-3118
}

\begin{abstract}
Biaxially textured thin films of Magnesium Oxide (MgO) where deposited on metal foils as epitaxial template layers for secondgeneration high- $T_{c}$ superconducting tapes. The $\mathrm{MgO}$ films where deposited using electron beam evaporation on substrates inclined to the atomic vapor. The processing dependence of biaxial texture on inclination angle, deposition rate, film thickness and substrate was investigated by four-circle $x$-ray diffraction (XRD) and selected-area electron diffraction (SAED). The texturing of the $\mathrm{MgO}$ is a selective growth process whereby the texture improves with increasing film thickness. This growth process differs from the texturing of $\mathrm{MgO}$ using ionbeam-assisted deposition (IBAD) which is nucleation controlled and requires an amorphous substrate. It was experimentally found that the in-plane texture of the MgO thick films, as measured from (220) phi scans, are not dependent on deposition rates from $\mathbf{2 . 5}$ to $100 \AA / \mathrm{sec}$, making this technique amiable to costeffective production scale-up. This has important implications on the manufacturing scale-up of YBCO coated tapes. The mechanism for the creation of biaxial texture in the $\mathrm{MgO}$ films was determined to be from the combined effects of the cubic equilibrium crystal habit of $\mathrm{MgO}$ and columnar self-shadowing.
\end{abstract}

\section{INTRODUCTION}

Ores ONSIDERABLE effort has been made in the last few years to create a robust technique for depositing long lengths of biaxially textured oxide films on metallic substrates. This effort has been manifested in a number of techniques such as ion-beam-assisted deposition (IBAD), rolling-assisted biaxially textured substrates (RABiTS) and by inclined-substrate deposition (ISD) using pulsed-laser sources. $[1,2,3]$ These deposition techniques require costly excimer lasers and/or complex deposition geometries. Evaporation is a simple low-cost deposition technique that allows for high deposition rates and has long been utilized in industry as a cost-effective deposition method for continuous coating applications. [4]

$\mathrm{MgO}$ has been used successfully as a buffer layer for YBCO grown on silicon, and metal substrates by IBAD. [5, 6] The requirement of an assisting ion gun and the addition of an amorphous $\mathrm{Si}_{3} \mathrm{~N}_{4}$ buffer layer, make the growth of biaxially textured $\mathrm{MgO}$ by IBAD considerably more complex than the simplicity of evaporation on an inclined substrate.

Manuscript received September 18, 2000.

Work supported in part by the U.S. Department of Energy (DOE), Energy Efficiency and Renewable Energy, as part of a DOE program to develop electric power technology, under Contract W-31-109-Eng-38.

"Current address: Semiconductor Research and Development Center, IBM Microelectronics, 33A, 2070 RTE 52, Hopewell Junction, NY 12533.
Preferred orientation in $\mathrm{MgO}$ films grown on inclined substrates was first observed by Aboelfotoh [7] but it wasn't until 1997 that Bauer et al. [8] applied this growth technique to coated conductors. This study investigates the effects of processing on the in-plane texture of $\mathrm{MgO}$ films grown on inclined substrates and the evolution of this texture as it pertains to developing a model for texture-development.

\section{EXPERIMENTAL PROCEDURE}

$\mathrm{MgO}$ thin films were deposited from a magnesium oxide source using electron beam evaporation. During deposition the substrates were inclined at varying angles, $\alpha$, with respect to the vapor source between $0^{\circ}$ and $60^{\circ}$. The deposition geometry is shown in Fig. 1. Oxygen was introduced to insure oxygen stoichiometry. The base pressure of the vacuum system was $1 \times 10^{-7}$ torr, which rose to an operating pressure of $2 \times 10^{-5}$ torr during evaporation. Deposition rates varied between 2.5 to $100 \AA / \mathrm{sec}$. ISD films were grown between $500 \AA$ and $5 \mu \mathrm{m}$ thick.

Biaxial texture was characterized with a four-circle $X$-ray diffractometer using $\mathrm{CuK} \alpha$ radiation. Out-of-plane texture was determined by the full-width-at-half-maximum (FWHM) of omega scans of the $\mathrm{MgO}(200)$ reflection, and in-plane texture was measured by the FWHM of phi scans of the MgO (220) reflection. Cross-sectional scanning electron and transmission electron microscopy (SEM and TEM respectively) were used to study the growth structure of the $\mathrm{MgO}$ thick films.

\section{RESULTS AND DISCUSSION}

MgO films grown at normal incidence $\left(\alpha=0^{\circ}\right)$ grow preferentially with the [111] direction normal to the substrate and the $(220)$ and (200) planes randomly oriented around this growth direction. The growth structure contains only out-ofplane texture, called fiber texture and is not useful for coated conductor applications were an in-plane texture is required. Fig. 2 shows $\mathrm{X}$-ray pole figures for $\mathrm{MgO}$ deposited with the atomic flux at normal incidence, showing the clearly defined fiber texture.

Increasing the inclination angle, $\alpha$, of the atomic flux, creates a sharp texture to develop in the $\mathrm{MgO}$ films when grown to a thickness of several microns. The c-axis of the magnesium oxide films grows off-axis with respect to the substrate normal due to the inclined angle, $\alpha$, of the incident atomic flux. The orientation angle, $\beta$, to which the $c$-axis is rotated with respect to the substrate-normal is dependent on the angle of inclination of the substrate, $\alpha$. A series of (200) and (220) pole figures for $\mathrm{MgO}$ films grown to a thickness of $2.5 \mu \mathrm{m}$ at inclination angles between 0 and $60^{\circ}$ at $10^{\circ}$ 


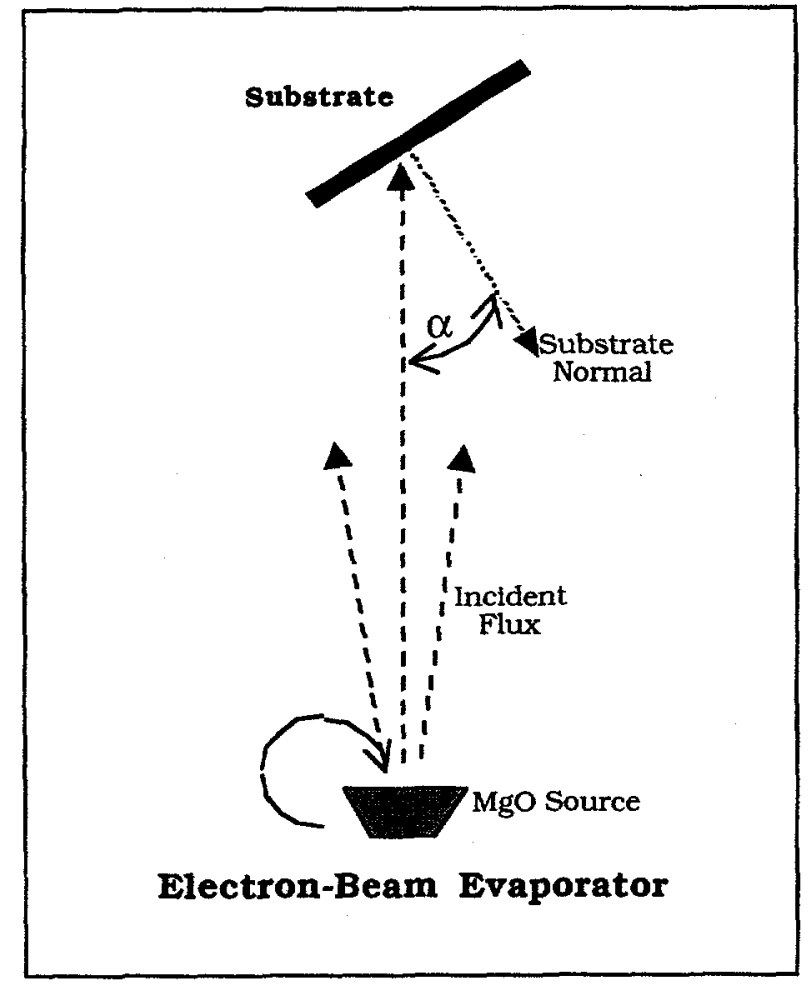

Fig. 1. Schematic of inclined-substrate deposition (ISD) geometry

intervals can be seen in fig. 3 . Figure 4 schematically shows the relative reference frame for subsequent discussion.

The in-plane texture in ISD-MgO improves with increasing inclination of the substrate, $\alpha$. The corresponding orientation angle, $\beta$, of the (200) faces rotates towards the vapor direction. Fig. 5 shows the results of the texture and orientation angle on the incident flux angle. The degree of in-plane texture of the $\mathrm{MgO}$ thick films grown by ISD did not exhibit a dependence on the deposition rate between 2.5 and $100 \AA / \mathrm{sec}$. Fig. 6 shows the lack of dependence of the in-plane texture as determined from (220) phi-scans on deposition rates from $2.5 \AA / \mathrm{sec}$ to $100 \AA / \mathrm{sec}$. This experimental observation is significant in that allows for the deposition of highly oriented films for coated conductor applications in a fraction of the time currently required for IBAD.

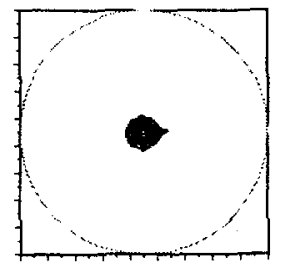

(111)

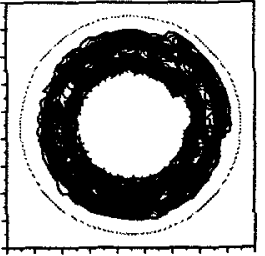

(200)

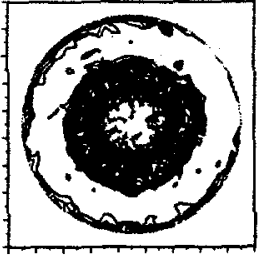

(220)
Fig. 2. X-ray pole figures for $\mathrm{MgO}$ with the atomic flux at normal incidence, $\alpha=0^{\circ}$. $0^{\circ}$

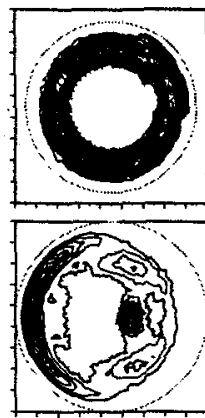

$20^{\circ}$

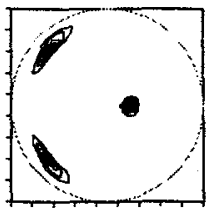

$\mathbf{3 0}^{\circ}$

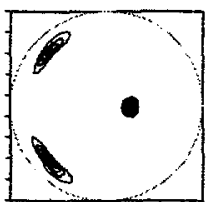

$40^{\circ}$

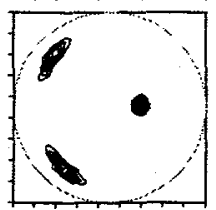

$50^{\circ}$

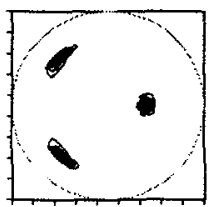

$60^{\circ}$

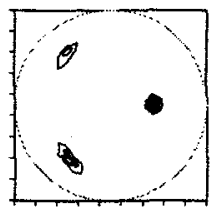

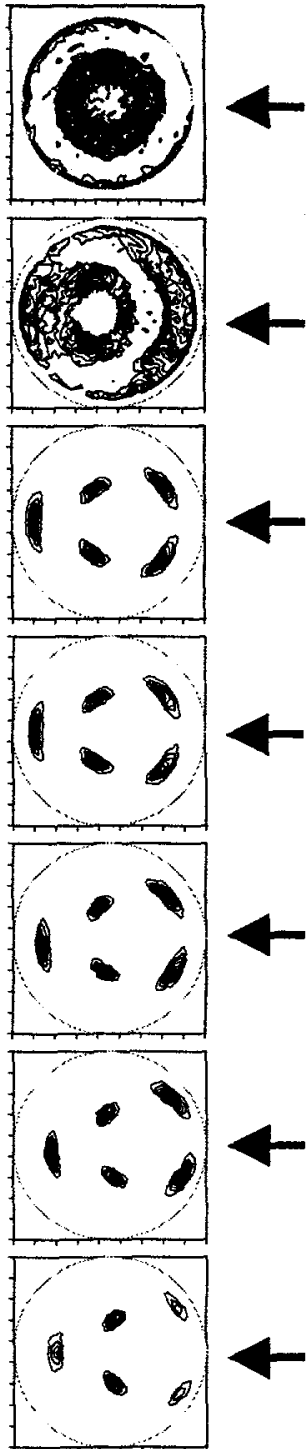

Fig. 3. (200) and (220) pole figures for MgO grown by ISD on Hastelloy C substrates as a function of inclination angle, $\alpha$. Arrows represent the vapor direction.

The texture of the MgO films improves with thickness as would be expected from a selective growth controlled microstructure. Films less than $1.0 \mu \mathrm{m}$ show little biaxial texture. [9] Films with thicknesses greater than $1.0 \mu \mathrm{m}$ show very sharp texture that improves with increasing film thickness. This thickness dependence of the in-plane texture as determined from (220) phi scans exhibits an exponential decay function that asymptotically approaches $8^{\circ}$ FWHM. Fig.7 shows the thickness dependence of the FWHM in ISD MgO thick films. Selective area diffraction (SAED) results from cross-sectional TEM show that this crossover thickness from randomly oriented film to well-textured is approximately $1 \mu \mathrm{m}$. [9] 


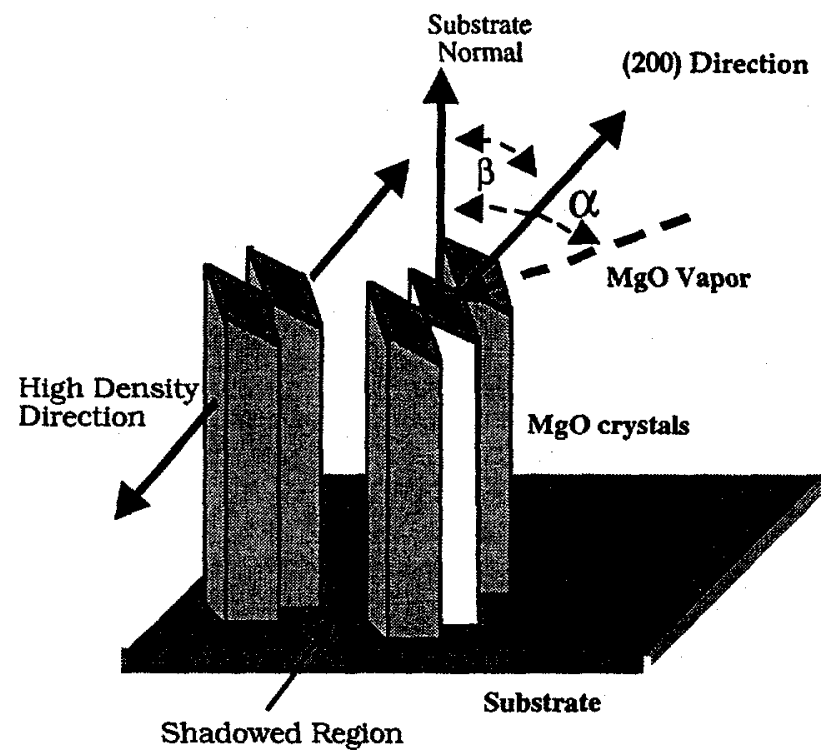

Fig. 4. Schematic of incident vapor and columnar growth directions.

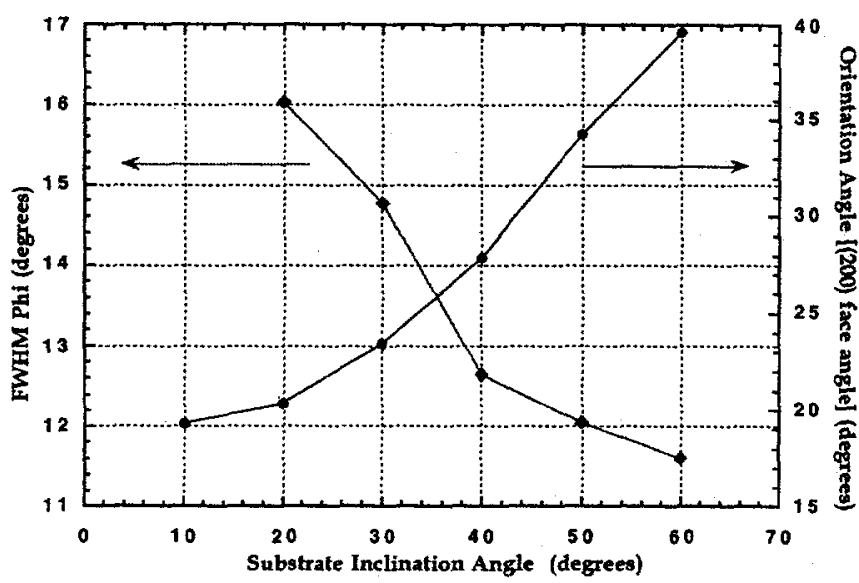

Fig. 5. Dependence of the (200) orientation angle of $\beta$, as a function of the inclination angle, $\alpha$.

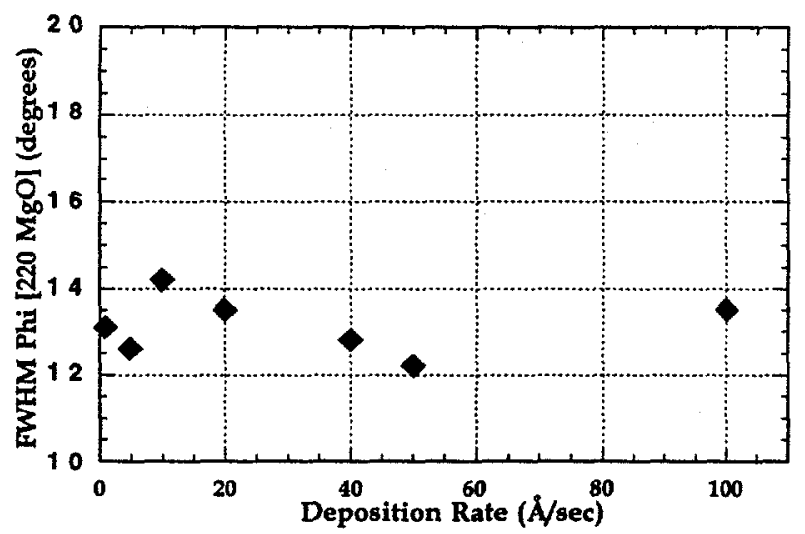

Fig. 6. FWHM in ISD $\mathrm{MgO}$ as a function of deposition rate.
At low deposition rates ( $10 \AA / \mathrm{sec})$ the $\mathrm{MgO}$ columns grow nominally straight up. This effect is a balance of the driving force for the columns to grow towards the vapor direction due to capturing the greatest number of incoming atoms, countered by the conservation of parallel momentum of the incoming flux, which drives the columns to grow away from the flux direction. [10] Cross-sectional TEM studies made of an ISD MgO films grown at $50 \AA / \mathrm{sec}$ shows that the $\mathrm{MgO}$ columns tend to grow away from the flux direction, because of the higher adatom momentum at higher deposition rates and at higher inclination angles $\alpha$, the columns grow away from the vapor.[9]

The $\mathrm{MgO}$ films grow with a distinct columnar structure at all angles. SEM fracture cross-sections by Koritala et al. shows that columns grow nominally parallel to the substrate normal despite the highly inclined angle of the atomic flux, indicating a large degree of surface diffusion. [9] The tops of the MgO columns are truncated by (200) planes as determined from selected-area electron diffraction (SAED) and correlated to images obtained using transmission electron microscopy. [9] These results agree with $x$-ray diffraction pole figures of $\mathrm{MgO}$ films.

Figure 8 shows a planar TEM image of an ISD-MgO thin film deposited at $55^{\circ}$. The TEM micrograph shows that the top of these columns are truncated by three planes, with the larger triangular plane facing the atomic flux and the other two planes symmetric about the incident plane. Correlating these results with that of SAED patterns verifies that these planes are (200) planes.

$\mathrm{MgO}$ is particularly well suited to inclined substrate deposition by electron beam evaporation, because it readily grows crystalline at room temperature without the need for additional surface adatom mobility due to the high $\mathrm{Mg}-\mathrm{O}$ binding energy. This is particularly important with e-beam evaporation because of the low energies $(0.1-\mathrm{leV})$ imparted by the process to the vapor atoms. [4] $\mathrm{MgO}$ has an out-ofplane preferred growth direction of [111]. This is in disagreement with Bauer [8] but has been observed in this study and by the original work by Aboelfotoh [7].

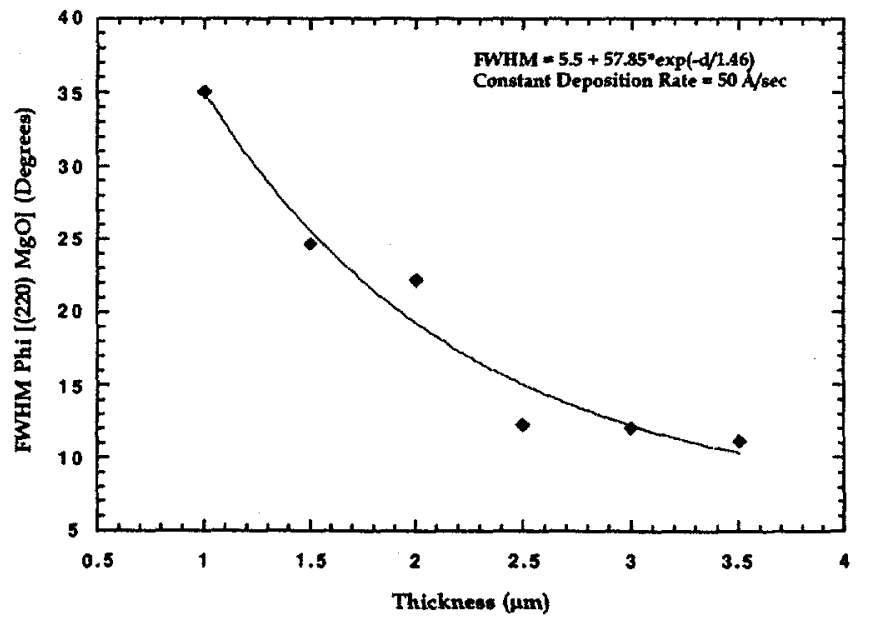

Fig. 7. FWHM in ISD MgO as a function of thickness. 


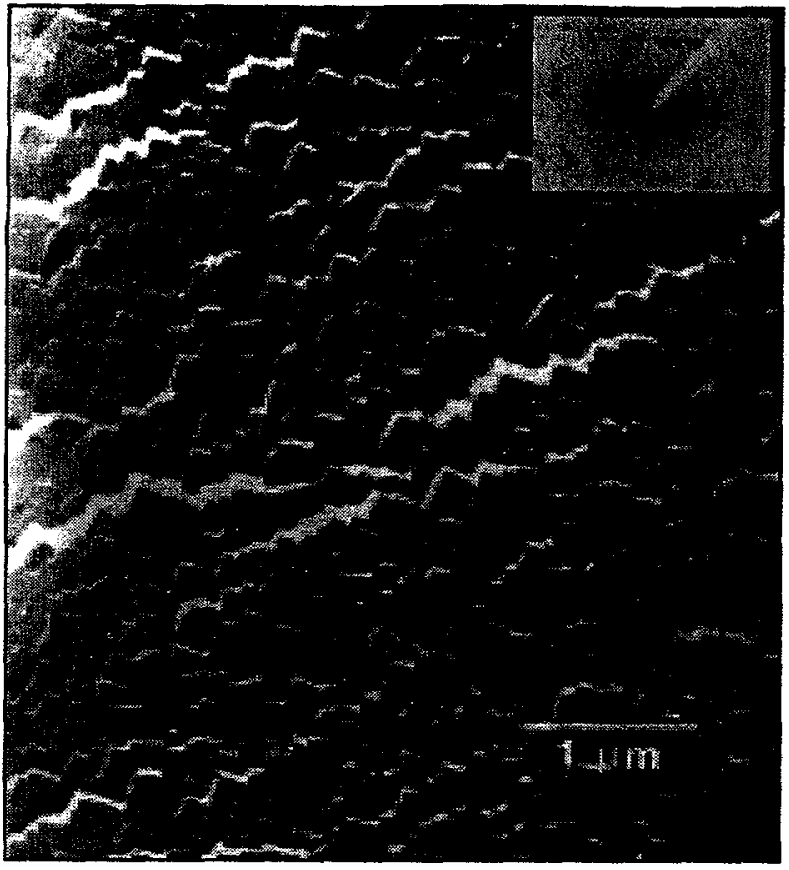

Fig. 8. Planar TEM image of ISD-MgO on silicon showing (100) facets.

The formation of biaxial texture is connected to the anisotropic growth rates of different crystal planes in $\mathrm{MgO}$ and the self-shadowing that occurs at inclined angles. [11] The crystal planes that grow at higher rates grow taller and eventually overshadow the slower growing grains. The shadowing prohibits the slower growing grains from contributing to the final texture in thick films. It is well known that the fast growth planes in $\mathrm{MgO}$ are the $\{100\}$ planes, yielding a cubic equilibrium crystal growth habit. [12]

TEM micrographs of the $\mathrm{MgO}$ thin films grown by ISD, by Koritala et al. clearly show that the MgO crystal habit is in fact cubic. [9] This result is not surprising due to the higher packing density in this direction and the lowering of surface free energy that is obtained by maximizing the (200) crystal faces. This crystal growth habit reduces polarity by obtaining neutral crystal planes with equal numbers of cations and anions on each crystal face.

In all observed growth conditions in this study and by those of Bauer, [8] the (200) directions rotations to face the vapor direction and not the (111) face. The [111] direction rotates to grow away from the vapor when the substrate is inclined. This observation suggests that the $\mathrm{MgO}$ crystals prefer to grow with the [111] direction perpendicular to the substrate while maintaining a minimization of surface free energy by maximizing the (200) surface area. Maximization of the (200) surface area per unit volume while maintaining the required [111] preferred growth direction perpendicular to the substrate is obtained by growing as pyramids. As the vapor direction is rotated away from the substrate normal by an angle, $\alpha$, the (100) crystal planes can only be maximized while maintaining the [111] preferred growth direction by balancing the two competing effects. This results in the observed columnar growth of MgO truncated with (100) faces, one of which is rotated to face the vapor direction.
The problem can be simplified by stating that the faces with the greater capture cross-section will grow towards the vapor. A greater capture cross-section can be achieved by maximizing the area per unit volume that the vapor can "see". If the argument was just area per unit volume, then a cube shape with a (200) face towards the vapor would be the ideal growth structure. However since four of the five exposed sides of the cube would essentially have a "zero" capture cross-section this can not be the case and in deed is not as verified by the (111) fiber texture observed in $\mathrm{MgO}$ films deposited at zero inclination, see fig. 2.

Columnar self-shadowing concerns the probability that an atom on the surface of the growing film will capture an atom from the atomic flux. Simply stated: only vapor atoms that can touch a surface atom will be captured. Columns with their fastest growth directions (greatest capture cross-section) perpendicular to the substrate will out-grow the slower growing columns, which become extinct as they intersect the column walls of the taller grains. [11] This grown mechanism is often called evolutionary texture as the well-oriented grains out grow the misoriented grains and with a sufficiently thick film, only a biaxially textured structure is left.

\section{CONCLUSIONS}

The texture and growth morphology of MgO films deposited by the ISD technique was investigated and found to depend on substrate inclination angle and the film thickness. An increase in the substrate inclination angle with respect to the atomic flux resulted in improved in-plane texture, which was as low as $10^{\circ} \mathrm{FWHM}$ in a $2.5-\mu \mathrm{m}$-thick film. The (200) plane grows towards the atomic flux to maximize its capture cross-section while competing with the fast growth [111] direction. The mechanism for the creation of biaxial texture in the $\mathrm{MgO}$ films was determined to be from the combined effects of the cubic equilibrium crystal habit of $\mathrm{MgO}$ and columnar self-shadowing. ISD has the advantage of being able to grow highly oriented $\mathrm{MgO}$ thick films at very high deposition rates on randomly oriented metal substrates. ISD $\mathrm{MgO}$ develops texture at a significantly faster rate than IBAD of YSZ.

\section{REFERENCES}

[1] Y. Iijima, N. Tanabe, O. Kohno, and Y. Okeno, "In-Plane aligned $\mathrm{YBa}_{2} \mathrm{Cu}_{3} \mathrm{O}_{7-\mathrm{x}}$ thin films deposited on polycrystalline metallic substrates," Appl. Phys. Lett., (60), 769, 1992.

[2] A. Goyal, D. Norton, J. Budai, M. Paranthaman, E. Specht, D. Kroeger, D. Christen, Q. He, B. Saffian, F. List, D. Lee, P. Martin, C. Klabunde, E. Hartfield, and V. Sikka, Appl. Phys. Lett.., 69, 12, $1795-7$ (1996).

[3] R.A. Doyle, W.A. Quinton, F. Baudnbacher, and W.Y. Liang, Physica C, 308, 169-174 (1998).

[4] D. Smith, Thin Film Deposition: Practices and Principles (McGrawHill, New York, 1995)

[5] C.P. Wang, K.B. Do, M. Beasley, T. Geballe, and R. Hammond, Appl. Phys. Lett. 71 (20), 2955-2957 (1997).

[6] J.R. Groves, P.N. Arendt, S.R. Foltyn, R. Depaula, E. Peterson, T. Holesinger, J. Coulter, R. Springer, C.P. Wang, and R. H. Hammond, IEEE Trans. On Appl. Supercond., 9, (2), 1964-66 (1999).

[7] M. O. Aboelfotoh, J. Vac. Sci. Tech., 10, 621 (1973).

[8] $M$. Bauer, $R$. Semerad, and $H$. Kinder, IEEE Trans. On Appl. Supercond, 9 (2) 1502-1505 (1999).

[9] R.E. Koritala, M.P. Chudzik, Z.P. Luo, D.J. Miller, C.R. Kannewurf, and U. Balachandran, To be presented at the Appl. Supercond. Conference, Virginia Beach, VA. Sept, 2000.

[10] L. Abelmann and C. Lodder, Thin Solid Films, 305, 1-21 (1997)

[11] O. Karpenko, J.C. Bilello, and S.M. Yalisove, J. Appl. Phys., 82, (3), 1397-1403 (1997)

[12] A.F. Moodie and C.E. Warble, J. Crystal. Growth , 10, 26 (1971). 